\title{
Multi-level seismic rehabilitation of existing frame systems and subassemblies using FRP composites
}

\author{
S. Pampanin \\ Department of Civil Engineering, University of Canterbury, Christchurch, New Zealand \\ D. Bolognini, A. Pavese, G. Magenes, G.M. Calvi \\ Department of Structural Mechanics, University of Pavia, Italy
}

\begin{abstract}
The feasibility and efficiency of a retrofit intervention on gravity load-designed frame systems using externally bonded FRP composites is herein presented, through both analytical and experimental investigations. A multi-level retrofit strategy is proposed to achieve the desired performance, based on hierarchy of strength considerations. The expected sequence of events can be visualized through demand-capacity curves within M-N Performance-Domains. An analytical procedure able to predict the enhanced non-linear behaviour of the panel zone region, due to the application of CFRP laminates, in terms of shear strength (principal stresses) vs. shear deformation, is developed and proposed as a fundamental step for the definition of a proper retrofit strategy. The experimental results from quasi-static tests on $2 / 3$ scaled beam-column subassemblies (either interior and exterior) in as-built and retrofitted configuration, provided very satisfactory confirmations of the viability and reliability of the retrofit solution adopted as well as of the proposed analytical procedure.
\end{abstract}

\section{INTRODUCTION}

Extensive experimental-analytical investigations on the seismic performance of existing reinforced concrete frame buildings, designed for gravity loads only, as typically found in most seismic-prone countries before the introduction of adequate seismic design code provisions in the 1970 's, confirmed the expected inherent weaknesses of these systems (Aycardi et al., 1994; Beres et al., 1996, Hakuto et al., 2000, Park, 2002; Pampanin et al., 2002; Bing et al., 2002; Calvi et al., 2002a,b). As a consequence of poor reinforcement detailing, lack of transverse reinforcement in the joint region as well as absence of any capacity design principles, brittle failure mechanisms were observed. At a local level, most of the damage is likely to occur in the beam-column joint panel zone while the formation of soft-story mechanisms can greatly impair the global structural performance of these RC frame systems. An appropriate retrofit strategy is therefore required, which is capable of providing adequate protection to the joint region while modifying the hierarchy of strengths between the different components of the beamcolumn connections according to a capacity design philosophy.

Alternative retrofit and strengthening solutions have been studied in the past and adopted in practical applications. A comprehensive overview of traditional seismic rehabilitation techniques was presented by Sugano (1996). Conventional techniques which utilize braces, jacketing or infills as well as more recent approaches including base isolation and supplemental damping devices have been considered. Most of these retrofit techniques have evolved in viable upgrades. However, issues of costs, invasiveness, and practical implementation still remain the most challenging aspects of these solutions. Preliminary investigations on a non-invasive and economical retrofit solution based on metallic haunch connections have, for example, been recently presented by Pampanin \& Christopoulos (2003).

In the past decade, an increased interest in the use of advanced non-metallic materials, including Shape Memory Alloys, SMA (Dolce et al. 2000), or Fibre Reinforced Polymers, FRP (fib 2001), has been observed.

In this contribution, the feasibility and efficiency of a retrofitting intervention using FRP composite materials, according to a multi-level performancebased approach will be presented. Depending on the joint typology (interior or exterior) and on the structural details adopted, alternative objectives can be achieved in terms of hierarchy of strength within the beam-column-joint system.

The theoretical developments of the retrofit strategy as well as the characteristic of the simplified analytical model adopted to evaluate the increase in shear strength in the joint panel zone region will be described. The results from experimental quasi-static tests on as-built and CFRP retrofitted beam-column subassemblies (either exterior and interior), 2/3 
scaled, will be presented. Extremely satisfactory performance of the retrofitted specimens was observed: the desired hierarchy of strength and sequence of events, according to the proposed multi-level design strategy, were achieved as targeted and wellpredicted by the analytical methods.

\section{SEISMIC RESPONSE OF EXISTING POORLY DETAILED BUILDINGS}

\subsection{Experimental results}

The first phase of the research project involved the assessment, through analytical and experimental investigations, of the seismic vulnerability of existing reinforced concrete frame systems, primarily designed for gravity-loads as typical of the period between 1950s\&1970s, before the introduction of modern seismic design provisions in the mid-1970s.

The experimental program, part of a cocoordinated national project, comprised of quasistatic tests carried out at the Laboratory of the Department of Structural Mechanics of the University of Pavia on six, 2/3 scaled, beam-column joint subassemblies (two exterior knee-joints, two exterior Tee-joints and two interior joints, Fig. 1) as well as on a three-storey three bays frame system. Particular attention was given to the vulnerability of the panel zone region. An overview of the results will be herein given while more details can be found in Pampanin et al. (2002) and Calvi et al. (2002b).


Figure 1. Geometry and reinforcement details in exterior joint specimen $\mathrm{T} 1$ and interior specimen $\mathrm{C} 2$

Table 1 reports the fundamental geometric and reinforcement details of section of the beam-column subassemblies specimens: both identifications corresponding to as-built and retrofitted configurations (discussed later in the contribution) are indicated.

Table 1. Specimen reinforcement and section geometry

\begin{tabular}{|c|c|c|c|c|c|}
\hline Joint type & Specimen & & $\begin{array}{c}\text { Section } \\
\text { dimensions }\end{array}$ & $\begin{array}{l}\text { Longitudinal } \\
\text { reinforcement }\end{array}$ & $\begin{array}{c}\text { Transverse } \\
\text { reinforcement }\end{array}$ \\
\hline \multirow{3}{*}{ Exterior tee } & T1A, T1B $^{* * *}$ & Beam & $330 \times 200$ mm* & $\begin{array}{c}\text { Top } 2 \phi 8+2 \phi 12 ; \text { Bottom } \\
2 \phi 8+2 \phi 12\end{array}$ & $\phi 4 @ 115 \mathrm{~mm}^{*}$ \\
\hline & & Column & $200 \times 200 \mathrm{~mm}^{*}$ & $3 \phi 8+3 \phi 8^{*}$ & $\phi 4 @ 135 \mathrm{~mm}^{*}$ \\
\hline & $\mathbf{T} 2 \mathrm{~A}, \mathrm{~T}^{2} \mathrm{~B}^{* *}$ & $\begin{array}{l}\text { Beam } \\
\text { Column }\end{array}$ & & $\begin{array}{c}\text { Top } 2 \phi 8+1 \phi 12 ; \text { Bottom } \\
2 \phi 8+1 \phi 12\end{array}$ & \\
\hline \multirow{2}{*}{ Interior } & $\mathbf{C} 1^{* *}, \mathbf{C} 3^{* *}$ & $\begin{array}{l}\text { Beam } \\
\text { Column }\end{array}$ & & $\begin{array}{c}\text { Top } 2 \phi 8+3 \phi 12 ; \text { Bottom } \\
2 \phi 8+1 \phi 12\end{array}$ & \\
\hline & $\mathrm{C} 2, \mathrm{C} 4$ & $\begin{array}{c}\text { Beam } \\
\text { Column }\end{array}$ & & $\begin{array}{c}\text { Top } 2 \phi 8+2 \phi 12 ; \text { Bottom } \\
2 \phi 8+1 \phi 12\end{array}$ & \\
\hline
\end{tabular}

The testing loading protocol for the beam-column subassemblies (set-up shown in Fig. 2, left side) consisted of increased level of lateral top displacements (series of three cycles) combined with a variation of axial load as a function of the lateral force, as would occur in a beam-column subassembly during the sway of the frame.

The exterior tee-joint specimens showed (at both subassembly and frame system level) a particular brittle hybrid failure mechanism given by joint shear damage combined with slippage of beam longitudinal (plain round) bars within the joint region with concentrated compressive force at the end-hook anchorage. As a result, a concrete "wedge" tended to spall off (Fig. 2 right side), leading to a brittle local failure and loss of bearing-load capacity (Fig. 3).

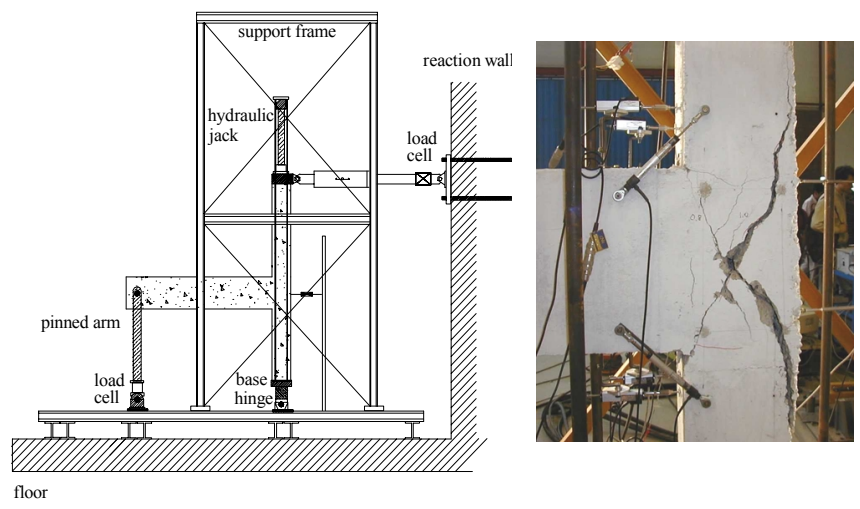

Figure 2. Test set-up and shear hinge mechanism in exterior joint (specimen T1)

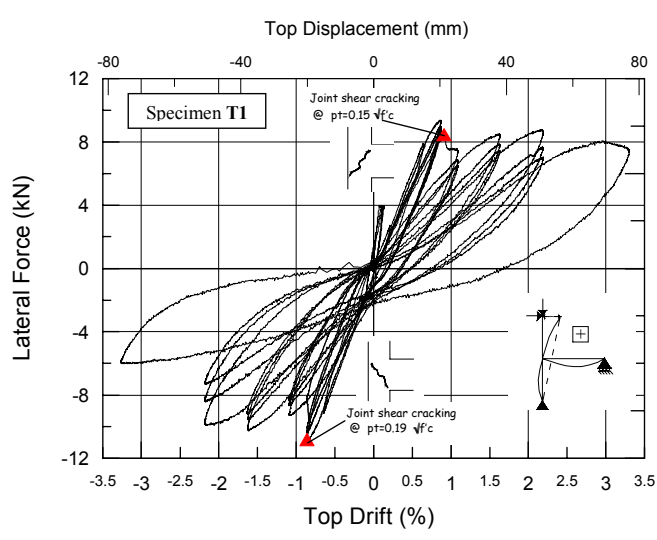

Figure 3. Hysteresis loop of exterior Tee-joint (specimen T1)

Conversely, the interior joint specimens showed significant resources of plastic deformation (Fig. 4), even without specific ductile structural details.

A marked pinching was still observed, due to slip of the column longitudinal reinforcement bars. According to preliminary capacity design considerations, shear joint cracking and column hinging were predicted to be relatively close events. The concentration of flexural damage in the column at early stages, thus, acted as a structural fuse for the joint panel zone, which did not suffer significant cracking and damage. However, it should be recalled that the 
global frame system response can be seriously impaired if column hinging leads to a soft-storey mechanism.

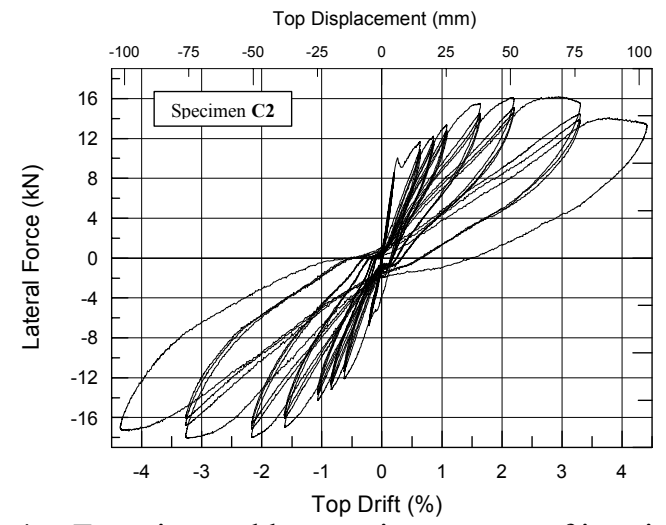

Figure 4. Experimental hysteretic response of interior joint (specimen $\mathrm{C} 2$ )

\subsection{Shear hinge mechanism and global response}

The experimental quasi-static tests on the three storey-three bays frame system (Calvi et al., 2002b) confirmed the high vulnerability of the panel zone region as observed at a subassembly level (particularly in exterior joints) and the tendency to develop undesirable global mechanisms, due to the absence of an adequate hierarchy of strength.

In particular, an interesting peculiar mechanism at global level was observed, when compared to a weak-column strong-beam mechanism (which would lead to a soft storey mechanism), typically expected in existing building.

Based on the experimental evidences and numerical investigations, the concept of a shear hinge mechanism has been proposed as an alternative to flexural plastic hinging in the beams (Pampanin et al. 2002, 2003). The concentration of shear deformation in the joint region, through the activation of a so-called "shear hinge", can reduce the deformation demand on adjacent structural members, postponing the occurrence of undesirable soft-storey mechanism (see Fig.5).

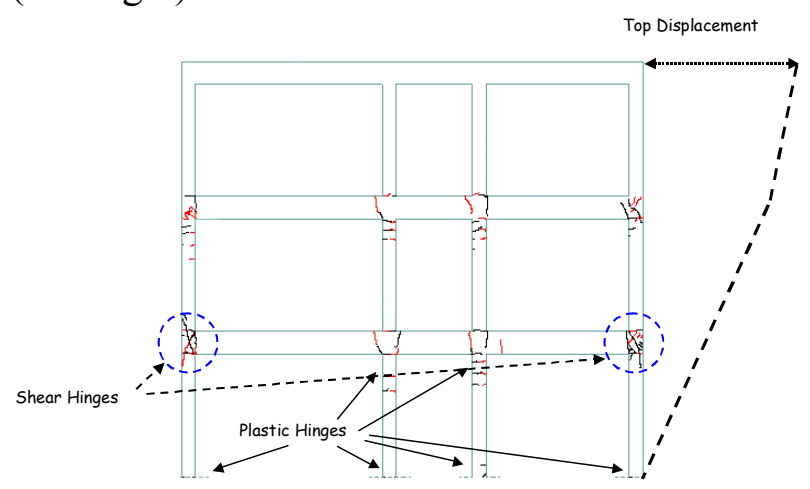

Figure 5. Frame response global mechanism: plastic hinges and shear hinges (top drift 1.6\%, Calvi et al. 2002b)

The drawback of this apparent favourable effect on the global response is the increase in shear deformations in the joint region which can possibly lead (depending on the joint typology and structural details adopted) to strength degradation and loss of vertical load-bearing capacity. The post-cracking behaviour of the joint depends, in fact, solely on the efficiency of the compression strut mechanism to transfer the shear within the joint. Thus, while rapid joint strength degradation after joint diagonal cracking is expected in exterior joints, an hardening behaviour after first diagonal cracking can be provided by an interior joint.

A critical discussion on the effects of damage and failure of beam-column joints in the seismic assessment of frame systems has been given in Calvi et al. (2002a). Limit states based on joint shear deformations have recently been defined and are reported in Pampanin et al. (2003). Based on a detailed assessment of the local damage and corresponding global mechanisms, a more reliable seismic rehabilitation strategy can be defined

\section{MULTI-LEVEL RETROFIT STRATEGY}

Independently on the technical solution adopted, the efficiency of a retrofit strategy strongly depends on a proper assessment of the internal hierarchy of strength of beam-column joints as well as of the expected sequence of events within a beam-column system (shear hinges in the joints or plastic hinges in beam and column elements). The effects of the expected damage mechanisms on the local and the global response should also be adequately considered.

\subsection{Performance-based retrofit strategy}

An ideal retrofit strategy would not only protect the joint panel zone region, identified critically weak point in older frames, but would further upgrade the structure to exhibit the desired weak-beam strongcolumn behaviour which is at the basis of the design of new seismic resistant RC frames. However, due to the disproportionate flexural capacity, in gravity load dominated frames, of the beams when compared to the columns a complete inversion of hierarchy of strengths is difficult to achieve in all cases and for all beam-to-column connections without major interventions. This is especially true for interior beam-to-column connections where the moment imposed on interior columns from the two framing beams is significantly larger than for exterior columns. As indicated in the previous paragraph, interior joints are less vulnerable than exterior joints and exhibit a much more stable hysteretic behaviour with hardening after first cracking. It is thus conceivable, in a bid to protect the interior columns from hinging, to tolerate some joint damage. According to a multilevel retrofit strategy approach suggested by Pam- 
panin \& Christopoulos (2003), two levels of retrofits can therefore be considered, depending on whether or not interior joints can be fully upgraded.

A complete retrofit would consist of a full upgrade by protecting all joint panel zones and developing plastic hinges in beams while columns are protected according to capacity design principles. A partial retrofit would consist of protecting exterior joints, forming plastic hinges in beams framing into exterior columns, while permitting hinging in interior columns or limited damage to interior joints, where a full reversal of the strength hierarchy is not possible. The viability of the partial retrofit strategy must be investigated on a case-by-case basis to assure that the localized damage to interior joints does not severely degrade the overall response of the structure or jeopardize the ability of the interior columns to safely carry gravity loads.

\subsection{Assessment of sequence of events: performance domains}

A simple procedure to compare the internal hierarchy of strengths within a beam-column-joint system is herein presented. The evaluation of the expected sequence of events is then proposed to be carried out through comparison of capacity and demand curves within a M-N (moment-axial load) performancedomain.

Figure 6 shows, as an example, the M-N performance domain adopted to predict the sequence of events and level of damage in the joint panel zone expected for the exterior specimen $\mathrm{T} 1$.

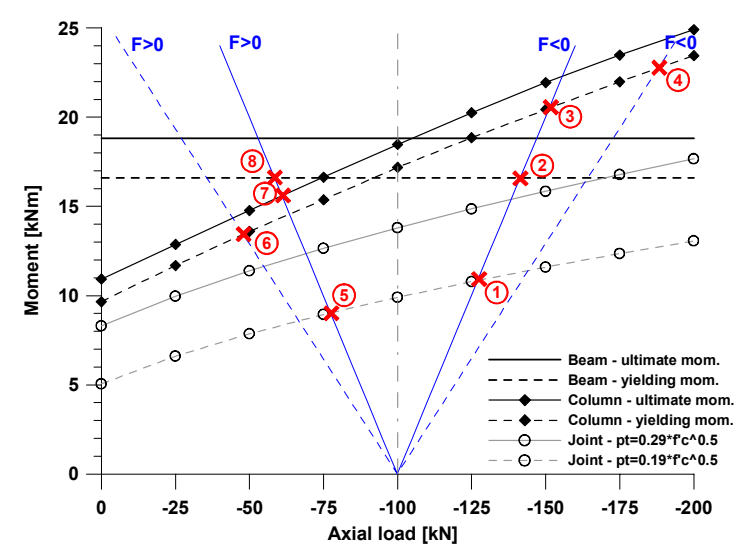

Figure 6. Evaluation of hierarchy of strengths and sequence of events: M-N Performance-Domain

(exterior Tee-joint T1 in as-built configuration)

The capacities of beam, column and joints are referred to a given limit state (e.g. for joints: cracking, equivalent "yielding" or extensive damage and collapse) and evaluated in terms of equivalent moment in the column at that stage, based on equilibrium considerations within the beam-column joint specimen. While the evaluation of $\mathrm{M}-\mathrm{N}$ curves for beams and columns is a relatively simple task, the definition of an "equivalent" curve to represent the joint panel zone can rely on the procedure described below.

Table 2. Sequence of events for exterior specimen T1 (as-built configuration)

\begin{tabular}{cccc}
\hline $\begin{array}{c}\text { Type of } \\
\text { lateral force }\end{array}$ & $\mathrm{N}^{\circ}$ & Specimen T1 (as-built) & $\begin{array}{c}\text { Lateral force } \\
{[\mathrm{kN}]}\end{array}$ \\
\hline & 1 & $\begin{array}{c}\text { Joint cracking and deterioration } \\
\text { starting } p_{t}=0.19 \sqrt{f_{c}}\end{array}$ & -10.94 \\
$\begin{array}{c}\text { Open joint } \\
\mathrm{F}<0\end{array}$ & 2 & Beam yielding & -16.59 \\
& 3 & Upper column yielding & -20.50 \\
& 4 & Lower column yielding & -22.75 \\
\hline & 5 & Joint failure & 9.37 \\
Close joint & 6 & Lower column yielding & 13.50 \\
$\mathrm{~F}>0$ & 7 & Upper column yielding & 14.50 \\
& 8 & Beam yielding & 16.59 \\
\hline
\end{tabular}

The capacity or damage level of a joint is typically expressed in terms of nominal shear stress $\left(v_{j n}\right)$ or principal compression/tensile stresses $\left(p_{c}, p_{t}\right)$. Although current codes (e.g. ACI 318-02, AIJ, EC8, NZS3101) tend to adopt simplified provisions which limit the nominal shear stress $v_{j n}$ expressed as function of the concrete tensile strength , $k_{1} \sqrt{f^{\prime}{ }_{c}}$, or the concrete compressive strength, $k_{2} f^{\prime}$, where $k_{1}$ and $k_{2}$ are empirical constants, it is commonly recognized that principal stresses, by taking into account the contribution of the actual axial compression stress acting in the column, can provide more accurate indications on the stress state and thus damage level in the joint region.

Typical strength degradation models, available in literature and based on research on poorly designed joints (e.g. Priestley, 1997, Pampanin et al., 2002, shown in Fig. 7) can be adopted to define limit states in a joint panel zone subjected to shear and axial load.

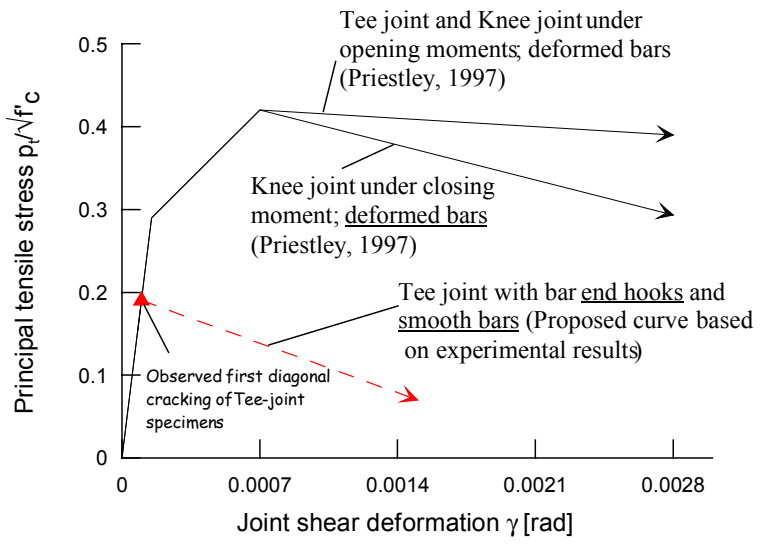

Figure 7. Strength degradation curves for exterior joints in terms of principal tensile stress- shear deformation

According to the simplified analytical model proposed by Pampanin et al. (2003) to describe the joint non-linear behaviour, based on a rotational spring within a concentrated plasticity approach, the equivalent moment-rotation curve of the joint region (i.e. monotonic characteristics of the spring model) 
can be derived from the corresponding principal tensile stress-shear deformation curve using equilibrium considerations: for any given level of principal tensile (or compression) stress in the joint, the corresponding "joint moment" $\mathrm{M}_{\mathrm{j}}$, which is either the sum of the beam moments or the sum of the column moments at that stage, can be evaluated.

So doing, M-N capacity curves corresponding to the different joint limit states can be plotted within a performance domain where "equivalent column" capacity are represented.

As shown in Fig. 6 (as-built exterior specimen T1), demand curves should account for the variation of axial load due to the effects of lateral forces in a frame system (for either opening and closing of the joint). Incorrect and non-conservative assessment of the sequence of events can otherwise result, leading to inadequate design of the retrofit intervention

In the case of specimen T1, in the as-built configuration, a pure shear hinge mechanism, with extensive damage of the joint, was thus expected (using a proper demand curve) prior to any hinging of beams or columns (Table 2), as confirmed by the experimental tests. However, the order and "distance" of the events strongly depends on the demand curve assumed. If a constant axial load curve was used (as shown in Fig. 6 for $\mathrm{N}=-100 \mathrm{kN}$ ), only a minor increase in the column strength (in addition to the joint strengthening) would have appeared necessary, leading to a column hinging occurring before the formation of a beam hinge (i.e. high risk of a soft storey mechanism even after the retrofit intervention).

The concept of a performance-domain could thus be extended from the purpose of assessing as-built systems and adopted to evaluate and control the feasibility and efficiency of any retrofit strategy on beam-column joints, provided that the effects of the retrofit solution on the single elements (beams, column or joint panel zone) can be simply and independently evaluated as described in the following paragraphs.

\section{FRP STRENGTHENING EFFECTS: ANALYTICAL MODEL}

The effects of a retrofit intervention with FRP composite materials, in the form of externally bonded reinforcement (EBR), on beam-column joint, in terms of flexural or shear capacity in beams, columns and panel zone region, is carried out through a step-bystep procedure. The occurrence of defined limit states (cracking, yielding, debonding, crushing and spalling of concrete, failure within the adopted materials) corresponding to given stress or strain value can thus be properly evaluated and controlled when designing the retrofit intervention. As mentioned and shown, an accurate prediction of the expected sequence of events, can thus be obtained through M-N performance-domains.
Analytical procedures available in literature are adopted and properly modified to account for debonding phenomena as well as, more importantly, for the effects of the variation of axial load onto the joint panel zone behaviour (critical issue typically neglected).

\subsection{Flexural FRP retrofit of beams and columns}

The enhanced flexural behaviour of a FRP retrofit beam or column critical section was evaluated though a fibre section analysis. Bernoulli-Navier hypothesis on plane sections remaining plane was assumed, considering fully composite action (bond) between the external FRP laminates and the concrete. Debonding was taken into account according to the model proposed by Holzenkämpfer (1994) (and adopted by the fib guidelines of FRP retrofit, 2001), and thus expected to occur at a strain limit level $\varepsilon_{d e b}=c_{1} \cdot \sqrt{\frac{f_{c t m}}{E_{f} t_{f}}}$, where $E_{f}$ is the FRP Emodulus, $f_{c t m}$ the mean value of concrete tensile strength, $s$ the thickness of the FRP laminate and $c_{1}$ an empirical coefficient taken as 0.64 for CFRP as suggested by Neubauer \& Rostasy (1997).

The material behaviour was defined through proper stress-strain relationships, as follows: Mander et al. (1988) model for concrete; Dodd-Restrepo model (1995) for steel and a linear-elastic rule for the FRP composite material, consistent with the properties supplied by the provider.

The moment-curvature behaviour of the critical section in presence of externally bonded FRP laminate can thus be evaluated for different level of axial load (Fig. 8) using an iterative procedure as typically done for R.C. sections.

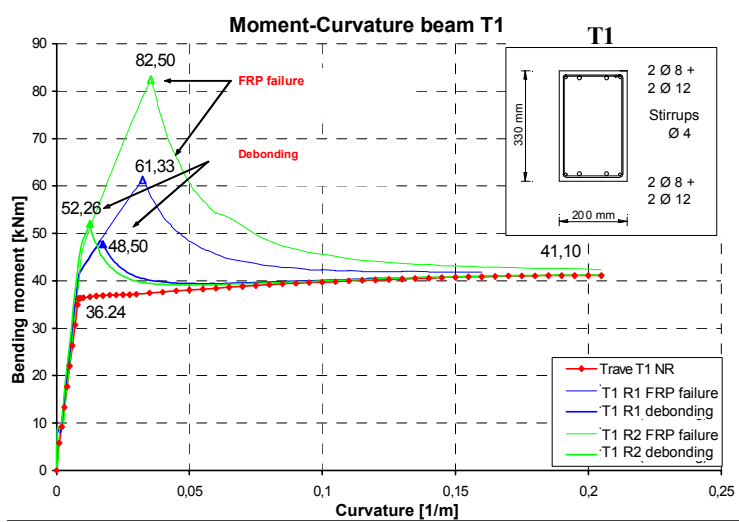

Figure 8. Effects of FRP on the moment-curvature curve of a member (beam) critical section

The position of the neutral axis is estimated until both compatibility and equilibrium conditions are satisfied. M-N capacity curves for beams and columns corresponding to a given limit state can be de- 
rived and plotted in a performance-domain to define the sequence of events.

The confinement effects of the FRP on the section curvature ductility capacity can be taken into account following procedures available in literature (e.g. Spoelstra \& Monti 1999).

\subsection{Shear FRP retrofit of joint}

The evaluation through analytical models of the strengthening effects on the panel zone (joint) shear is a more complex task with limited research available in the literature. An overview of alternative procedures has been given by Antonopoulos \& Triantafillou (2002). Typical over-simplified approaches consider the contribution of the FRP equivalent to external "stirrups" (analogy with steel transverse reinforcement). Upper limits of the maximum strain in the FRP material are used in the calculations, either corresponding to the declared ultimate tensile capacity (Gergely et al. 1998) or to a constant strain values depending on the preparation of the concrete surface (Tsonos \& Stylianidis, 1999; Gergely et al., 2000).

A more rigorous model, based on stress equilibrium and strain compatibility equations of the panel zone region (idealized as a three-dimensional element) has been presented by Antonopoulos \& Triantafillou (2002) as an extension of the model for RC joint behavior without FRP proposed by Pantazopoulou \& Bonacci (1992). Satisfactory validation of the analytical model was obtained on the experimental results on a total of 15 beam-column exterior beam-column subassemblies, tested by the authors (Antonopoulos \& Triantafillou, 2003) or available in literature (Gergely et al., 2000).

It is however important to underline that, as typically done in most experimental tests on beamcolumn joints, no variation of axial load as a function of the lateral force during the lateral sway of a frame system was considered during the tests. The implications of assuming a constant load in the assessment of sequence of event prior or after a retrofit intervention has been briefly discussed in the previous paragraphs.

In the present contribution the step-by-step iterative procedure proposed by Antonopoulos \& Triantafillou (2002) is adopted as a sound basis tool and extended after simple modifications, to separately evaluate the contribution of FRP on the concrete compression strength in terms of principal tensileshear deformation curve of the joint. As shown in Figure 9, the overall joint strength degradation curve would thus be given by the combination of the contributions of FRP and the concrete.

In terms of modelling according to a plasticity concentrated approach, two rotational springs (with moment-rotation curves derived, as mentione, according to the method proposed by Pampanin et al.,
2003) can be adopted to represent the two independent contributions.

It is in fact expected (later confirmed by the experimental tests) that the cracking and damage of the joint can still occur underneath the protection given by the FRP laminates, whose major effect is to increase the overall joint strength, avoiding local failure mechanism (as the "concrete wedge" mechanism) and achieving an enhanced global behaviour by developing a more desirable sequence of events (e.g. weak-beam strong-column mechanism if a total retrofit strategy is followed).

Details on the analytical procedure and simplified design method can be found in Vecchietti (2001) and Nassi (2002).

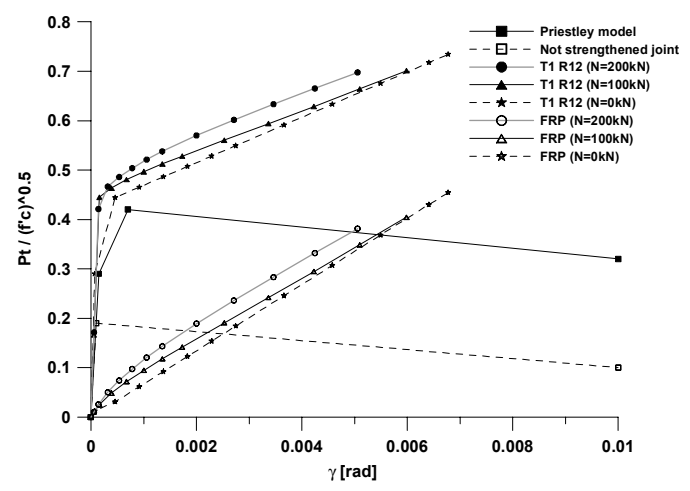

Figure 9. Joint strength degradation curve: contributions of FRP and concrete. (exterior speciment T1)

\section{DESIGN OF RETROFIT INTERVENTION}

According to the proposed multi-level retrofit strategy, a full retrofit was adopted for the exterior joint (protection of the joint and plastic hinge in the beam) while a partial retrofit was adopted for the interior joint specimen (partial protection of the column hinging while some damage in the joint region can be accepted).

Issues related to the expulsion of the concrete wedge in the exterior joints as well as to the premature debonding of the fibres were carefully considered as explained in the following sections.

\subsection{Retrofit Solutions}

Alternative FRP retrofit solutions (relying on different form or properties of the composite material) have been successfully proposed in literature and available. As mentioned, extensive experimental investigations on exterior beam-column joint retrofitted with FRP (in the form of laminates or strips) have been carried out by Triantafillou \& Antonopouos (2003). Due to the scope of that investigation (evaluation of FRP contribution to the joint shear strength), the design of the retrofit strategy aimed at guaranteeing that the damage occurred in the joint region. A selective seismic strengthening 
technique for gravity load designed frames, relying on both FRP laminates and NMS (Near Mounted Surface) has been recently proposed by Prota et al. (2002).

In this contribution, uni-directional carbon fiber laminates (high-modulus CFRP, Table 3) were adopted in the configurations illustrated in Figures 10 and 11 , for exterior joint and interior joint, respectively.

Table 3: Propertie of high modulus carbon fibre with unidirectional fabric (MBrace CFRP C5-30)

\begin{tabular}{cccccc}
\hline Fibre & $\begin{array}{c}\text { Density } \\
{\left[\mathbf{k g} / \mathbf{m}^{3}\right]}\end{array}$ & $\begin{array}{c}\text { Effective } \\
\text { thickness } \\
\text { of } \mathbf{1} \text { layer } \\
{[\mathbf{m m}]}\end{array}$ & $\begin{array}{c}\text { Characteristic } \\
\text { tensile } \\
\text { strength } \\
{[\mathbf{M P a}]}\end{array}$ & $\begin{array}{c}\text { Characteristic } \\
\text { modulus } \\
\text { of elasticity } \\
{[\mathbf{M P a}]}\end{array}$ & $\begin{array}{c}\text { Ultimate } \\
\text { strain } \\
{[\%]}\end{array}$ \\
\hline $\begin{array}{c}\text { High } \\
\text { modulus } \\
\text { carbon }\end{array}$ & 1820 & 0.165 & 3000 & 390000 & 0.8 \\
\hline
\end{tabular}

Vertical FRP laminates were used on the external face of the column in both interior and exterior joints (2 layers per side) in order to increase the column flexural capacity as well as the joint shear strength. In addition, in the exterior joint specimen, a U-shape horizontal laminate, wrapped around the exterior face of the specimen at the joint level, was used to increase the joint shear strength as well as prevent the expulsion of a concrete wedge.

An adequately limited anchorage length within the beam was calculated in order to guarantee sufficient shear strengthening in the joint without excessively increasing the beam capacity (as per Fig. 6). Although the evaluation of strengthening effects was carried out including debonding effects (when nonconservative), additional smaller strips were used to wrap the main FRP laminates and provide proper anchorage. In the case of the interior joint, the FRP laminate crossing the joint was intentionally left unprotected from debonding in the joint panel zone region.

The target performance of the retrofit solution was controlled using the proposed procedure and M$\mathrm{N}$ performance-domain as shown in Fig. 12 and Table 3 for the exterior specimen T1B.

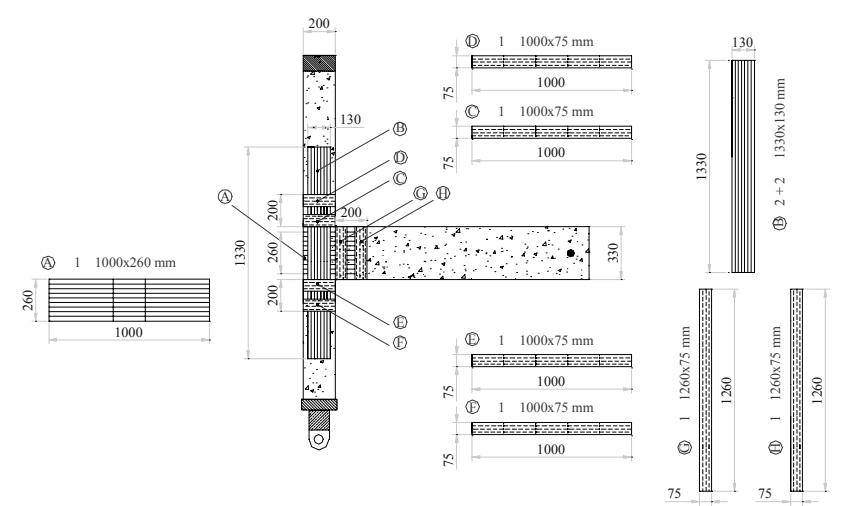

Figure 10 FRP-Retrofit solution for exterior joint (specimen T1B)

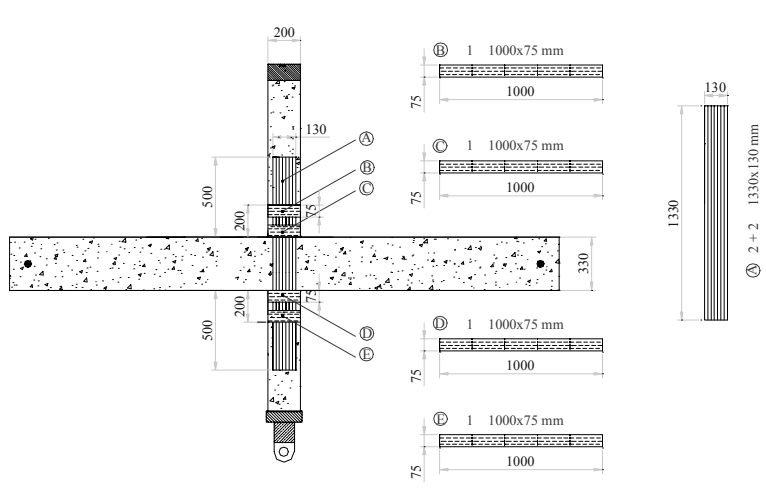

Figure 11. FRP-Retrofit solution for interior joint (specimen $\mathrm{C} 3$ )

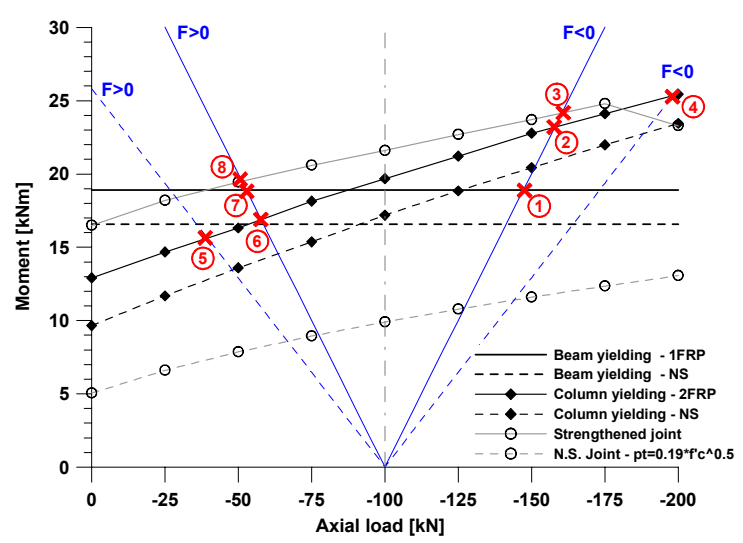

Figure 12. Evaluation of hierarchy of strengths and sequence of events: M-N Performance-Domain (exterior Tee-joint T1B joint after retrofit)

Table 4. Sequence of events for exterior specimen T1 (retrofit configuration)

\begin{tabular}{cccc}
\hline $\begin{array}{c}\text { Type of } \\
\text { lateral force }\end{array}$ & $\mathrm{N}^{\circ}$ & Specimen T1B (strengthened) & \\
\hline & 1 & Event & $\begin{array}{c}\text { Lateral force } \\
{[\mathrm{kN}]}\end{array}$ \\
\hline $\begin{array}{c}\text { Open joint } \\
\mathrm{F}<0\end{array}$ & 2 & Upper column yielding & -18.91 \\
& 3 & Joint cracking (no strength & -23.11 \\
& 4 & degradation) & -24.15 \\
& 5 & Lower column yielding & -25.32 \\
\hline Close joint & 6 & Upper column yielding & 15.75 \\
$\mathrm{~F}>0$ & 7 & Beam yielding & 16.98 \\
& 8 & Joint failure & 18.91 \\
& 8 & & 19.67 \\
\hline
\end{tabular}

\section{EXPERIMENTAL RESULTS}

The results of the experimental quasi-static tests on three beam column joints in the retrofitted configurations (namely $\mathrm{T} 1 \mathrm{~B}, \mathrm{~T} 2 \mathrm{~B}$, and $\mathrm{C} 3$, with the test on $\mathrm{C} 1$ being under preparation) provided very satisfactory confirmations of the efficiency of the adopted retrofit solution as well as of the reliability of the analytical procedure developed to design the intervention and assess the expected sequence of events and performance. A summary of the results is herein given, while more details are available in Nassi (2002) and will be reported in future publications. 
In all cases, the retrofit objective based on a multi/level retrofit strategy was achieved, leading to a significantly improvement in the behaviour of the subassemblies, which ultimately imply an enhanced behaviour of the frame system (adequate global inelastic mechanism).

As shown in Figure 13, a properly designed FRPretrofit solution can protect and avoid the formation of a brittle shear hinge mechanism and reestablished a more desirable hierarchy of internal strengths and sequence of events, enforcing a beam plastic hinge mechanism (total retrofit).

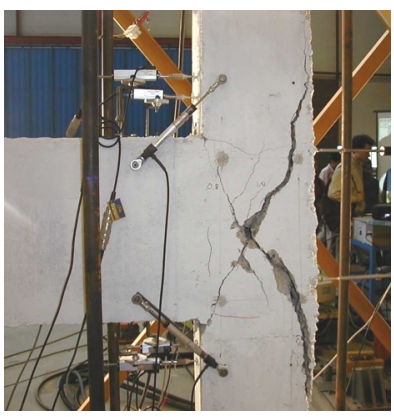

a)

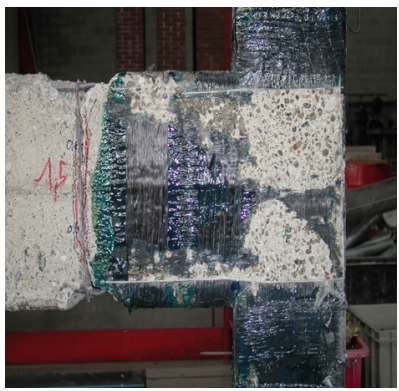

b)
Figure 13: Alternative damage mechanisms; a) shear hinge (asbuilt T1); (b) beam plastic hinge (retrofitted T1B)

As a result, an improved and more stable hysteresis behaviour was observed with increased ductility and energy dissipation capacity (Figs. 14 and 15).

The values of lateral force corresponding to the occurrence of the critical events were well-predicted by the analytical methods (presented in Fig. 12 and Table 4).

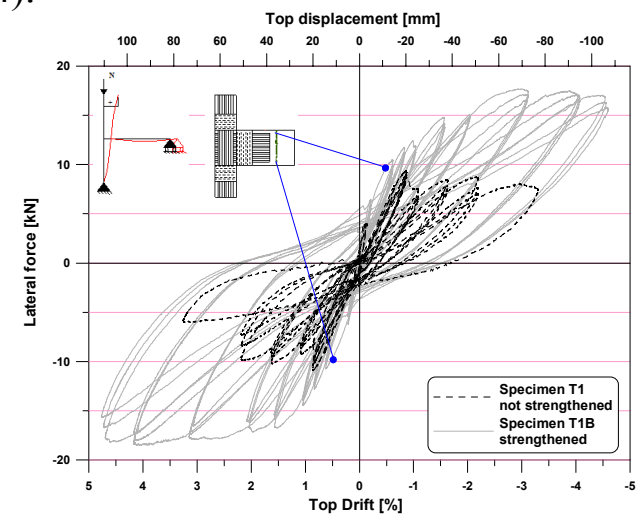

Figure 14 Comparison of hysteresis behavior of as-built and FRP-retrofitted configuration: exterior specimen T1B

Similar considerations can be derived for the interior joint (specimen C3, Fig. 16) where the partial retrofit strategy led to a controlled debonding of the column vertical fibres crossing the joint. The formation of flexural damage in the column was thus postponed. In addition to the increased overall strength, the FRP provided a favourable confinement effects in the column plastic hinge region avoiding the premature crushing and spalling of concrete cover, protecting from strength degradation, buckling of the longitudinal bars and consequent failure.

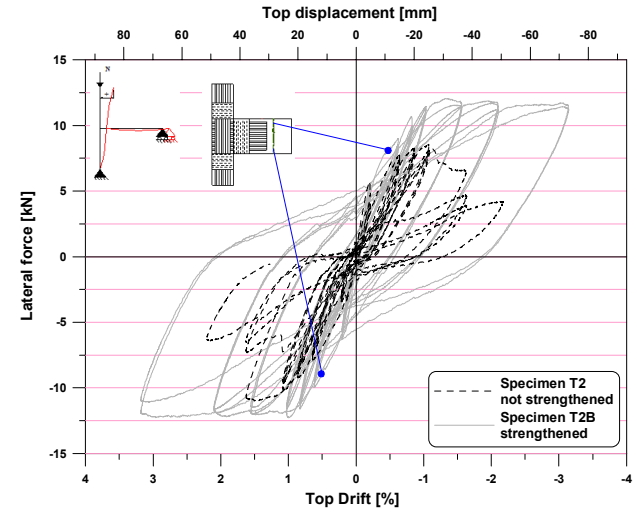

Figure 15 Comparison of hysteresis behavior of as-built and FRP-retrofitted configuration: exterior specimen T2B

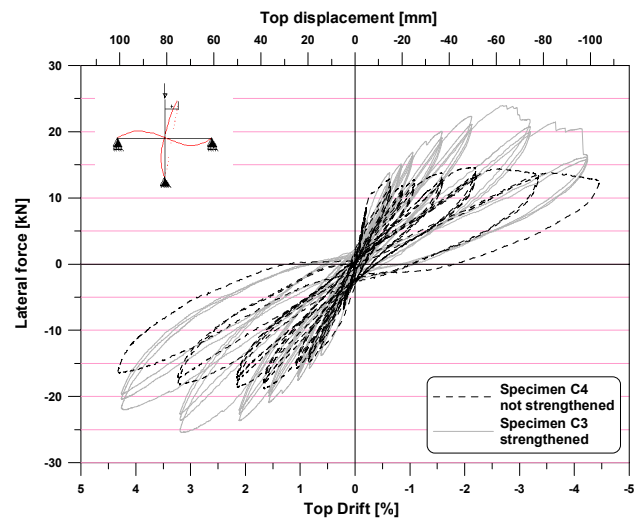

Figure 16 Comparison of hysteresis behavior of as-built and FRP-retrofitted configuration: exterior specimen T2B

Moreover, preliminary analytical-experimental comparison of the joint behaviour in terms of principal tensile stress vs. shear deformation curve confirmed the efficiency of the adopted analytical model in evaluating the strengthening effects of FRP on the joint shear strength.

\section{CONCLUSIVE REMARKS}

The preliminary results of quasi-static tests on beamcolumn joint specimens, designed for gravity load only and retrofitted with CFRP laminates, provided very satisfactory confirmation of the efficiency of similar solutions for existing buildings.

A multi-level retrofit strategy depending on the subassemblies type and structural details has been proposed to achieve the desired performance with a feasible intervention. A simplified procedure to evaluate and control the sequence of event using $\mathrm{M}$ $\mathrm{N}$ performance-domain has been presented.

In the exterior joint, the occurrence of a brittle joint shear mechanism was adequately protected and a more desirable hierarchy of strengths and sequence of events achieved, leading to a more ductile and dissipating hysteresis behaviour.

Similar retrofit procedure and solutions have been adopted on a three storey frame system, whose experimental quasi-static tests is on preparation and will be conducted by middle of the year. The results from the test on the retrofitted configuration as well as comparisons with the performance of the as-built 
configurations (Calvi et al. 2002b), will allow to further validate the efficiency of the proposed retrofit strategy concept and methods.

Ultimately, as discussed in the introduction, issues of accessibility of the joint region and invasiveness will be faced in real applications. It is worth however noting that a typical geometrical and plan configuration of existing buildings designed for gravity load only in the 1950s-1970s period consist of frames running in one direction only and lightly reinforced slab in the orthogonal direction, the latter being quite typical of the construction practice in Mediterranean countries. In these cases, the adoption of the proposed retrofit intervention can be somehow facilitated, when compared with more recently designed buildings with frames in both directions and cast-in-situ concrete slabs providing flange effects.

\section{ACKNOWLEDGMENTS}

The financial support provided by the Italian Ministry of the University and the University of Pavia, under a coordinated national Project (PRIN 2001), as well as by the European Community (SPEAR G6RD-CT-2001-00525) is gratefully acknowledged. The authors wish to thank the MAC S.p.a. Treviso for providing the materials and technical assistance for the retrofit intervention. The assistance and cooperation, during different phases of the project, of the postgraduate students Mr. A. Vecchietti and Mr. R. Nassi are also kindly acknowledged.

\section{REFERENCES}

ACI Committee 318 2002. Building Code Requirements for Structural Concrete (ACI 318-02), American Concrete Institute, Farmington Hills, Mich., 391 pp.

AIJ, Architectural Institute of Japan 1997. Design Guidelines for Earthquake-Resistant R.C. Buildings Based on Inelastic Displacement Concept (draft, in Japanese).

Aycardi, L., E., Mander, J., B. \& Reinhorn, A.M. 1994. Seismic Resistance of R.C. Frame Structures Designed Only for Gravity Loads: Experimental Performance of Subassemblages, ACI Structural Journal, Vol. 91, No.5, 552-563.

Antonopoulos, C.P.\& Triantafillou, T.C. 2002. Analysis of FRP-strengthened RC beam-column joints, Journal of Composites for Construction, Vol. 6, no.1, pp. 41-51.

Antonopoulos, C.P.\& Triantafillou, T.C. 2003. Experimental Investigation on FRP-Strengthened RC Beam-Column Joints, J.l of Composites for Construction, 7(1), pp. 39-43.

Beres, A., Pessiki, S., White, R., Gergely, P. 1996. Implications of Experimental on the Seismic Behaviour of Gravity Load Designed RC Beam-Column Connections, Earthquake Spectra, Vol. 12, No.2, May, pp. 185-198.

Bing. L, Yiming W. \& Tso-Chien P. 2002. Seismic Behavior of Non-Seismically Detailed Interior Beam-Wide Column Joints. Part I: Experimental Results and Observed Behavior, ACI Structural Journal, Vol. 99, N. 6.

Calvi G.M., Magenes G. \& Pampanin S. 2002a. Relevance of Beam-Column Damage and Collapse in RC Frame Assessment. J. of Earthq. Engng (JEE), Special Issue 1, pp.75-100
Calvi, G.M., Magenes, G. \& Pampanin, S. 2002b. Experimental Test on a Three Storey R.C. Frame Designed for Gravity Only, 12th ECEE, London, paper n. 727.

Dolce, M., Cardone, D.\& Marnetto, R. 2000. Implementation and testing of passive control devices based on shape memory alloys. Earthq. Engng. \& Struct. Dyn., 29, 7, 945-968.

Dodd, L.L., \& Restrepo, J.I. 1995. Model for Predicting Cyclic Behavior of Reinforcing Steel. ASCE Journal of Structural Engineering, Vol. 121, No. 3, pp. 433-445.

Eurocode 8, 2003 Design Provisions for Earthquake Resistance of Structures, European Committee for Standardization, Brussels.

fib (Federation International du Beton) 2001. Externally Bonded FRP Reinforcement for RC structures, fib Bulletin n.14, Lausanne.

Gergely, J., Pantelides, C. P., Nuismer, R.J. \& Reaveley, L.D. 1988. Bridge Pier Retrofit Using Fibre Reinforced Plastic Composites, Journal of Composite Constructions, ASCE, 2(4), 165-174.

Gergely, J., Pantelides, C. P. \& Reaveley, L.D. 2000. Shear Strengthening of RC T-Joints Using CFRP composites, Journal of Composite Constructions, ASCE, 4(2), 56-64.

Hakuto, S., Park, R. and Tanaka, H. 2000. Seismic Load Tests on Interior and Exterior Beam-Column Joints with Substandard Reinforcing Details, ACI Structural Journal, V. 97, N.1, 11-25.

Holzenkämpfer, P. 1994. Ingenieurmodelle des verbundes geklebter bewehrung für betonbauteile, Dissertation, TU Braunshwieg (in German).

Mander, J.B., Priestley, M.J.N. and Park R., 1988. Theoretical Stress-Strain Model for Confined Concrete, ASCE Journal of the Structural Division, Vol. 114, No. 8, pp. 1804-1826.

Nassi, R. 2002. Seismic Retrofit Strategy for Under-Designed Beam-Column Subassemblies Using FRP, Laurea Thesis, Dept. of Struct. Mech., Un. of Pavia (in Italian).

Neubauer \& Rostásy, 1997. Design aspects of concrete structures strengthened with externally bonded CFRP-plates, Concrete+Composites, 7th International Conference on Structural Faults and Repair, 2, 109-118.

NZS3101, 1995. Part 1 The design of Concrete Structures, Standards New Zealand.

Pampanin, S., Calvi, G.M. \& Moratti, M. 2002. Seismic Behaviour of R.C. Beam-Column Joints Designed for Gravity Loads, 12th ECEE, London, paper n. 726.

Pampanin, S., Christopoulos, C. 2003. Non-invasive Retrofit of Existing RC Frames Designed for Gravity Loads only, fib2003 Symp. Concrete Struct. in Seismic Regions, Athens.

Pampanin, S., Magenes, G. \& Carr, A.. 2003. Modelling of Shear Hinge Mechanism in poorly Detailed RC BeamColumn Joints, Proceedings of the fib Symposium Concrete Structures in Seismic Regions, Athens, paper n. 171.

Pantazopoulou, S.,J. \& Bonacci, J.F. 1994. On earthquakeresistance reinforced concrete frame connections. Canadian Journal of Civil Engineering. 21, 307-328.

Park, R. 2002. A Summary of Results of Simulated Seismic Load Tests on Reinforced Concrete Beam-Column Joints, Beams and Columns with Substandard Reinforcing Details. Journal of Earthquake Engineering, Vol. 6, No. 2, 1-27.

Priestley, M.J.N. 1997. Displacement-based Seismic Assessment of Reinforced Concrete Buildings", Journal of Earthquake Engineering, Vol. 1, No. 1, 157-192.

Prota, A., Manfredi, G., Nanni, A. \& Cosenza, E. 2002. Capacity Assessment of GLD RC Frames Strengthened with FR, 12th European Conference on Earthquake Engineering, London, paper n. 241.

Spoelstra, M.R: \& Monti, G. 1999. FRP-Confined Concrete Model. J. of Composites for Constr., ASCE, 3(3), 143-150. 
Sugano, S. 1996. State of the art in Techniques for Rehabilitation of Buildings, Proceedings of the 11th World Conf. on Earth. Engng., Acapulco, Mexico, Paper no. 2175.

Tsonos, A.D: \& Stylianidis, K.A., 1999. Pre-Seismic and PostSeismic Strengthening of Reinforced Concrete Structural Subassemblages Using Composite Materials (FRP), Proceedings, $13^{\text {th }}$ Hellenic Concrete Conference, Rethymno, Greece, 1, 455-466 8in Greek).

Vecchietti, A., 2001. Seismic Rehabilitation of Concrete Frame Systems Designed for Gravity Loads Only Using FRP Composite Materials, Laurea Thesis, Dept. of Structural Mechanics, University of Pavia (in Italian) 